\title{
O QUE É ECOLOGIA DE PAISAGENS?
}

\author{
Jean Paul Metzger
}

Biota Neotropica v1 http://www.biotaneotropica.org.br/v1n12/pt/abstract?thematic-review+BN00701122001

\author{
Recebido em 01 de outubro de 2001 \\ Publicado em 28 de novembro de 2001 \\ Laboratório de Ecologia de Paisagens e Conservação - LEPaC \\ Departamento de Ecologia, Instituto de Biociências USP \\ Rua do Matão, 321, travessa 14 \\ 05508-900, São Paulo, SP \\ Fone: 113818.7564 \\ Fax: 113813.4151 \\ Jpm@ib.usp.br
}

\begin{abstract}
Landscape ecology is a new subject in ecology characterized by two main approaches: a geographical one, which studies how man affects and manages landscapes; and an ecological one, which emphasizes the effects of spatial structure on ecological processes and the importance of these relationships for conservation purposes. The construction of a common theoretical foundation is a difficult task with the coexistence of different and conflicting notions and definitions from these two approaches. In the present work, I present a unified notion of landscape as "a heterogeneous mosaic composed by interactive landscape units, where heterogeneity exists for at least one parameter, one specific observer and at a particular scale". The heterogeneity is essentially interpreted through the "human eyes" in the geographical approach and through the "eyes" of other species or communities in the ecological perspective. The proposed landscape definition also shows that landscape does not necessarily correspond to broad spatial scales or a new biological level, just above the ecosystem. The scale and the biological level will be determined by the observer or the studied species. Landscape ecology is promoting a paradigm shift in fragmentation and biological conservation studies as far as it integrates the spatial heterogeneity and the concept of scale in the ecological analysis, transforming ecology in a more useful science for environmental problem solving.
\end{abstract}

Key Words: Landscape ecology, landscape, heterogeneity, scale, conservation.

\section{Resumo}

A ecologia de paisagens é uma nova área de conhecimento dentro da ecologia, marcada pela existência de duas principais abordagens: uma geográfica, que privilegia o estudo da influência do homem sobre a paisagem e a gestão do território; e outra ecológica, que enfatiza a importância do contexto espacial sobre os processos ecológicos, e a importância destas relações em termos de conservação biológica. Estas abordagens apresentam conceitos e definições distintas e por vezes conflitantes, que dificultam a concepção de um arcabouço teórico comum. Nesse trabalho, proponho uma definição integradora de paisagem como sendo "um mosaico heterogêneo formado por unidades interativas, sendo esta heterogeneidade existente para pelo menos um fator, segundo um observador e numa determinada escala de observação". Esse "mosaico heterogêneo" é essencialmente visto pelos olhos do homem, na abordagem geográfica, e pelo olhar das espécies ou comunidades estudadas na abordagem ecológica. O conceito de paisagem proposto evidencia ainda que a paisagem não é obrigatoriamente um amplo espaço geográfico ou um novo nível hierárquico de estudo em ecologia, justo acima de ecossistemas, pois a escala e o nível biológico de análise dependem do observador e do objeto de estudo. A ecologia de paisagens vem promovendo uma mudança de paradigma nos estudos sobre fragmentação e conservação de espécies e ecossistemas, pois permite a integração da heterogeneidade espacial e do conceito de escala na análise ecológica, tornando esses trabalhos ainda mais aplicados para resolução de problemas ambientais.

Palavras-chave: Ecologia de paisagens, paisagem, heterogeneidade, escala, conservação. 


\section{Introdução}

A ecologia de paisagens é considerada uma área de conhecimento emergente, em busca de arcabouços teóricos e conceituais sólidos (Hobbs 1994). O jargão utilizado é por muitas vezes impreciso e ambíguo, refletindo uma disciplina que ainda busca se definir e superar o impasse criado pelas diferentes visões de paisagem dos seus pesquisadores (Wiens 1999). Esta heterogeneidade de visões está intimamente ligada à existência de duas abordagens distintas de ecologia de paisagens: uma nascida na Europa, em meados do século passado, e outra mais jovem, que surgiu a partir de um workshop norte-americano em Illinois (Risser et al. 1984). Apesar das nítidas diferenças das abordagens, o pleno desenvolvimento da ecologia de paisagens necessita de definições claras e integradoras. Neste trabalho, procura-se retratar as duas abordagens de ecologia de paisagens, propor uma noção integradora de paisagem e apresentar as novas perspectivas que a ecologia de paisagens traz para a ecologia. Para facilitar a leitura, um pequeno glossário dos termos mais utilizados em ecologia de paisagens é apresentado em anexo.

\section{As duas principais abordagens de paisagem}

\section{Visões de paisagem}

A primeira referência à palavra "paisagem" na literatura aparece no "Livro dos Salmos", poemas líricos do antigo testamento, escritos por volta de 1000 A.C. em hebraico por diversos autores, mas atribuídos na maioria ao rei Davi. Esses poemas eram cantados nos ofícios divinos do Templo de Jerusalém, e depois foram aceitos pela Igreja cristã como parte de sua liturgia. No "Livro dos Salmos", a paisagem refere-se à bela vista que se tem do conjunto de Jerusalém, com os templos, castelos e palacetes do Rei Salomão. Essa noção inicial, visual e estética, foi adotada em seguida pela literatura e pelas artes em geral, principalmente pela pintura na segunda metade do século XVIII. Além do retrato real da beleza da natureza, os pintores e escritores pré-românticos e românticos, assim como os simbolistas e os impressionistas, retratavam também a paisagem como um reflexo da "paisagem interior", dos sentimentos de melancolia e solidão.

Atualmente, na linguagem comum, a paisagem é definida como "um espaço de terreno que se abrange num lance de vista" (dicionário Aurélio). A palavra "paisagem" possui, assim, conotações diversas em função do contexto e da pessoa que a usa. Pintores, geógrafos, geólogos, arquitetos, ecólogos, todos têm uma interpretação própria do que é uma paisagem. Apesar da diversidade de conceitos, a noção de espaço aberto, espaço "vivenciado" ou de espaço de inter-relação do homem com o seu ambiente está imbuída na maior parte dessas definições. Esse espaço é vivenciado de diferentes formas, através de uma projeção de sentimentos ou emoções pessoais, da contemplação de uma beleza cênica, da organização ou planejamento da ocupação territorial, da domesticação ou modificação da natureza segundo padrões sociais, do entendimento das relações da biota com o seu ambiente, ou como cenário/palco de eventos históricos. A paisagem como noção de "espaço", ganhando sentido ou utilidade através do "olho" ou da "percepção" de um observador, pode ser o conceito principal de confluência dessas diferentes "visões".

Em todos os casos, há sempre uma noção de amplitude, de distanciamento. A paisagem nunca está no primeiro plano, pois ela é o que se vê de longe, de um ponto alto. Sempre precisamos nos distanciar para observá-la e, de certa forma, a paisagem é o lugar onde não estamos (pois observamos), podendo até ser um "pano de fundo". A observação, a percepção e as múltiplas compreensões/interpretações da paisagem sempre são feitas pelas lentes ou filtros da formação científica e da cultura do observador. E justamente por essa razão, por ser uma unidade visual, a paisagem não pode ser definida de forma universal, sem considerar a lente ou o filtro do observador.

No âmbito científico, a primeira pessoa a introduzir o termo "paisagem" foi um geo-botânico, Alexander von Humboldt, no início do século XIX, no sentido de "característica total de uma região terrestre". Em 1939, o termo "ecologia de paisagens" foi pela primeira vez empregado pelo biogeógrafo alemão Carl Troll (1899/1975), apenas quatro anos após Tansley (1935) ter introduzido o conceito de "ecossistema". O ponto de partida da ecologia de paisagens é muito semelhante ao da ecologia de ecossistemas: a observação das inter-relações da biota (incluindo o homem) com o seu ambiente, formando um todo. No entanto, a definição de paisagem difere grandemente da definição de ecossistema. Enquanto Tansley, ao definir ecossistema, deixa claro que se trata de um "sistema", onde há inter-dependência de seus componentes, existência de um ciclo de matéria e de mecanismos de auto-regulação (Troppmair 2000), para Troll (1971) a noção básica de paisagem é a espacialidade, a heterogeneidade do espaço onde o homem habita. A paisagem não se caracteriza, a princípio, por ter as propriedades de um "sistema" (ver adiante). O ecólogo da paisagem tem uma preocupação maior em estudar a heterogeneidade espacial (i.e., relações horizontais), o que contrasta com a visão do ecólogo de ecossistema, que busca entender as interações de uma comunidade com o sistema abiótico (i.e., relações verticais) num ambiente relativamente homogêneo. A entidade espacial heterogênea, que constitui uma paisagem, engloba aspectos geomorfológicos e de recobrimento, tanto naturais quanto culturais (Delpoux 1974). Esta noção visual, espacial e global está profundamente impregnada nas abordagens atuais de ecologia de paisagens.

\section{As abordagens "geográficas" e "ecológicas"}

A ecologia de paisagens caracteriza-se por um duplo nascimento e, conseqüentemente, por duas visões distintas da paisagem.

$\mathrm{O}$ primeiro surgimento da ecologia de paisagens 
foi impulsionado por Carl Troll e por pesquisadores, essencialmente geógrafos, da Europa Oriental e da Alemanha. Essa abordagem teve forte influência da geografia humana, da fitossociologia e da biogeografia, e de disciplinas da geografia ou da arquitetura relacionadas com o planejamento regional. Três pontos fundamentais caracterizam essa "abordagem geográfica": a preocupação com o planejamento da ocupação territorial, através do conhecimento dos limites e das potencialidades de uso econômico de cada "unidade da paisagem" (definida, nessa abordagem, como um espaço de terreno com características comuns); o estudo de paisagens fundamentalmente modificadas pelo homem, as "paisagens culturais" (Tricart 1979), que predominam no espaço europeu; e a análise de amplas áreas espaciais, sendo a Ecologia de Paisagens diferenciada, nessa abordagem, por enfocar questões em macro-escalas, tanto espaciais quanto temporais (sendo assim uma macroecologia). Nessa perspectiva, a paisagem é definida por Troll (1971) como "a entidade visual e espacial total do espaço vivido pelo homem" ("the total spatial and visual entity of human living space", apud Naveh \& Lieberman 1994). Fica clara, dentro desta perspectiva, a preocupação com o estudo das inter-relações do homem com o seu espaço de vida e com as aplicações práticas na solução de problemas ambientais (Barrett \& Bohlen 1991, Naveh \& Lieberman 1994). A ecologia de paisagens, desta forma, é menos centrada nos estudos bio-ecológicos (relações entre animais, plantas e ambiente abiótico), e pode ser definida como uma disciplina holística, integradora de ciências sociais (sociologia, geografia humana), geo-físicas (geografia física, geologia, geomorfologia) e biológicas (ecologia, fitossociologia, biogeografia), visando, em particular, a compreensão global da paisagem (essencialmente "cultural") e o ordenamento territorial.

O segundo surgimento da ecologia de paisagens se deu mais recentemente, na década de 1980, influenciado particularmente por biogeógrafos e ecólogos americanos que procuravam adaptar a teoria de biogeografia de ilhas para o planejamento de reservas naturais em ambientes continentais. Essa "nova" ecologia de paisagens foi inicialmente influenciada pela ecologia de ecossistemas, pela modelagem e análise espacial. Seu desenvolvimento beneficiou-se muito do advento das imagens de satélite (nos anos 1970-80), e das facilidades de tratamento de imagens e de análises geo-estatísticas propiciadas pela popularização dos computadores pessoais. Essa "abordagem ecológica", contrariamente à primeira, dá maior ênfase às paisagens naturais ou a unidades naturais da paisagem, à aplicação de conceitos da ecologia de paisagens para a conservação da diversidade biológica e ao manejo de recursos naturais, e não enfatiza obrigatoriamente macro-escalas. A escala espaçotemporal de análise dependerá da espécie em estudo. A paisagem é definida como: i) uma área heterogênea composta por conjuntos interativos de ecossistemas ("a heterogeneous land of area composed of a cluster of interacting ecosystems", Forman \& Godron 1986); ii) um mosaico de relevos, tipos de vegetação e formas de ocupação ("a mosaic of heterogeneous land forms, vegetation types and land uses" Urban et al. 1987); iii) uma área espacialmente heterogênea ("a spatially heterogeneous area", Turner 1989). A principal problemática nessa abordagem é o estudo dos efeitos da estrutura espacial da paisagem sobre os processos ecológicos (Turner 1989). Inicialmente, esta abordagem foi fortemente influenciada pelas facilidades de análise de imagens de satélite, tendo desenvolvido uma vasta literatura sobre procedimentos e métricas de quantificação da estrutura da paisagem (Turner \& Gardner 1991, Riitters et al. 1995, McGarigal \& Marks 1995, Gustafson 1998). Mais recentemente, essa análise detalhada do padrão espacial está sendo associada a processos ecológicos, como a propagação do fogo, a dispersão de sementes ou o deslocamento de animais em paisagens heterogêneas (por exemplo, Joly et al. 2001, Renjifo 2001, Summerville \& Crist 2001).

\section{As ecologias de paisagens}

As definições de ecologia de paisagens variam em função da abordagem ("geográfica" ou "ecológica") e dos autores. A ecologia de paisagens é entendida como: o estudo da estrutura, função e dinâmica de áreas heterogêneas compostas por ecossistemas interativos (Forman \& Godron 1986); a investigação da estrutura e funcionamento de ecossistemas na escala da paisagem (Pojar et al. 1994); uma área de conhecimento que dá ênfase às escalas espaciais amplas e aos efeitos ecológicos do padrão de distribuição espacial dos ecossistemas (Turner 1989); uma forma de considerar a heterogeneidade ambiental em termos espacialmente explícitos (Wiens et al. 1993); uma área de conhecimento que considera o desenvolvimento e a dinâmica da heterogeneidade espacial, as interações e trocas espaciais e temporais através de paisagens heterogêneas, as influências da heterogeneidade espacial nos processos bióticos e abióticos e o manejo da heterogeneidade espacial (Risser et al. 1984); uma ciência interdisciplinar que lida com as interações entre a sociedade humana e seu espaço de vida, natural e construído (Naveh \& Lieberman 1994).

Essas definições mostram uma nítida bifurcação no foco principal de interesse do ecólogo da paisagem. De um lado, há uma ecologia humana de paisagens, centrada nas interações do homem com seu ambiente, onde a paisagem é vista como o fruto da interação da sociedade com a natureza. Essa é a linha seguida pela "abordagem geográfica", representada aqui pela definição de Naveh \& Lieberman (1994). De outro lado, há uma ecologia espacial de paisagens, particularmente preocupada na compreensão das consequiências do padrão espacial (i.e., a forma pela qual a heterogeneidade se expressa espacialmente) nos processos ecológicos (ver definições acima de Richard Forman, Monica Turner e John Wiens). Esta é a linha principal de pesquisa na "abordagem ecológica".

No entanto, essas abordagens não são tão distintas 
quanto parecem, sendo inclusive um dos principais desafios da sociedade internacional de ecologia de paisagens (http://www.crle.uoguelph.ca/iale/) a unificação dos conceitos básicos e o estabelecimento de um sólido arcabouço teórico comum (Wiens 1996). É com a intenção de caminhar nesse sentido que uma noção integradora de paisagem é proposta.

\section{Uma noção integradora de paisagem A Paisagem}

Numa conceituação mais abrangente, em relação às definições anteriores, propõe-se que a paisagem seja definida como "um mosaico heterogêneo formado por unidades interativas, sendo esta heterogeneidade existente para pelo menos um fator, segundo um observador e numa determinada escala de observação".

Dentro da abordagem "geográfica" da ecologia de paisagens, o mosaico heterogêneo estará sendo visto através dos olhos do homem, de suas necessidades, anseios e planos de ocupação territorial. Como o homem age em amplas extensões de seu território, neste caso a ecologia de paisagens lida obrigatoriamente com escalas espaciais (e, por conseguinte, temporais) amplas, podendo ter vários quilômetros quadrados (segundo Forman 1995, "landscape is a mosaic where a cluster of local ecosystems is repeated in similar form over a kilometers-wide area"). O conjunto interativo da paisagem é então composto por "ecossistemas" ou por unidades de "cobertura" ou de "uso e ocupação do território", sendo que a escolha de umas dessas três formas de representar as unidades da paisagem é feita (arbitrariamente) pelo observador. Os limites entre esses conjuntos interativos da paisagem seriam então definidos por três fatores: o ambiente abiótico (formas de relevo, tipos de solo, dinâmica hidro-geomorfológica, parâmetros climáticos, em particular), as perturbações naturais (fogo, tornados, enchentes, erupções vulcânicas, geadas, por exemplo) e antrópicas (fragmentação e alteração de habitats, desmatamento, criação de reservatórios, implantação de estradas, entre outros). Estes fatores condicionam, em primeiro lugar, a presença de determinadas unidades. Por exemplo, na planície litorânea paulista é encontrado um mosaico de áreas de vegetações sobre restinga, mangues e áreas de uso e ocupação humana, que se distingue do mosaico encontrado nas escarpas da serra do Mar (floresta atlântica em diferentes estádios de sucessão, áreas de escorregamento, riachos e corredeiras) ou no Planalto Paulista (extensas áreas de uso antrópico, como cidades, pastagens e culturas, com fragmentos de vegetação natural e vegetações ripárias). Em segundo lugar, o padrão de ocupação humana e o ambiente abiótico condicionam também a disposição espacial das unidades no mosaico. Por exemplo, dentro do Planalto Paulista, paisagens contendo as mesmas unidades podem diferir muito em função do parcelamento das propriedades. As paisagens onde há um intenso parcelamento das propriedades privadas vão apresentar mosaicos extremamente heterogêneos, contendo muitos fragmentos pequenos de vegetação e parcelas reduzidas de campos agrícolas ou de pastagens. Por outro lado, paisagens em áreas de latifúndio vão ser muito mais homogêneas, com áreas agrícolas contínuas e remanescentes de vegetação geralmente reduzidos a pequenas manchas ou corredores ripários. Diferenças semelhantes podem ser observadas em função do relevo: regiões mais acidentadas tendem a ter paisagens mais complexas e menos modificadas pelo homem em relação a regiões de relevo plano. Cada conjunto interativo, caracterizado por uma composição em unidades e um padrão espacial, forma uma paisagem (a "paisagem" é por muitas vezes denominada como "unidade de paisagem" na abordagem geográfica; ver glossário).

Na abordagem "ecológica", o mosaico é considerado como um conjunto de habitats que apresentam condições mais ou menos favoráveis para a espécie ou a comunidade estudada. Desta forma, o olhar sobre a paisagem é feito através destas espécies, de suas características biológicas, em particular de seus requerimentos em termos de área de vida, alimentação, abrigo e reprodução. Dentro desta perspectiva, a escala espaço-temporal de análise não é obrigatoriamente ampla, como na primeira abordagem, pois ela depende da escala de ação/percepção da espécie/comunidade em estudo. Assim, para um gafanhoto pode existir um mosaico de manchas interativas numa área de apenas $4 \mathrm{~km}^{2}$ de extensão, sendo esse mosaico formado por manchas mais ou menos densas de herbáceas. Por outro lado, se considerarmos o mosaico de habitats para uma onça-parda (Puma concolor), este pode ser definido em escalas espaciais semelhantes às usadas para a ocupação humana. A definição das unidades e da extensão do mosaico depende das espécies: um mesmo espaço geográfico pode ser percebido como paisagens (mosaicos interativos) totalmente diferentes em função das características destas espécies.

\section{Escalas e níveis hierárquicos}

As definições tradicionais de paisagem associam, em geral, a paisagem com "uma" escala de análise mais global e a "um" nível hierárquico justo acima de ecossistemas, dando um sentido mais restrito à ecologia de paisagens do que o proposto no presente artigo. A noção integradora de "paisagem" proposta desfaz esses preconceitos. Primeiro, a ecologia de paisagens não pode ser mais considerada como sendo uma ecologia de macroescalas. A escala é definida pelo observador, resultando em análises em micro-escalas ou macro-escalas em função, em particular, do tamanho e da capacidade de deslocamento da(s) espécie(s) considerada(s). Muitos estudos em ecologia de paisagens procuram aprofundar o conhecimento da ecologia de paisagens enfocando pequenos organismos, como a fauna associada a musgos (Gonzales et al. 1998) ou pequenos coleópteros (Wiens \& Milne 1989, Metzger no prelo). A principal vantagem destas micro-paisagens está no fato de haver uma maior possibilidade de manipular o sistema, criando microexperiências com diversas replicações e controles (Metzger 
noprelo).

A nova noção de paisagem também não pode ser definida a priori como um novo nível hierárquico, justo acima do de ecossistema, como está implícito na maioria das definições de paisagem ("mosaico interativo de ecossistemas", segundo Naveh \& Lieberman 1994, Forman 1995). Num sistema, as propriedades de um nível hierárquico " $\mathrm{N}$ " dependem das interações ou associações existentes no nível "N-1" e são condicionadas (limitadas) pelo nível "N+1". Por exemplo, o funcionamento de uma proteína depende da configuração espacial dos aminoácidos que a compõem, pois em função dessa configuração a proteína será capaz de se associar a determinados receptores. Ademais, a expressão da proteína dependerá da existência no seu ambiente (nível "N+1") dos receptores adequados. $\mathrm{O}$ que a ecologia de paisagens quer mostrar, como veremos mais adiante, é que a disposição espacial de suas unidades (nível "N-1") condiciona o funcionamento da paisagem (nível "N"). É possível que esta propriedade seja verificada a posteriori, denotando a existência de uma hierarquia. No entanto, essa hierarquia não obedece obrigatoriamente os níveis usualmente reconhecidos em ecologia: populações comunidades - ecossistemas - paisagens. As unidades da paisagem não são obrigatoriamente "ecossistemas", noção que acarreta uma visão sistêmica onde há inter-dependência dos componentes, existência de um ciclo de matéria e de mecanismos de auto-regulação, que tornam o ecossistema um sistema auto-organizado (Odum 1971). As unidades são, em geral, as unidades de uso/ocupação e cobertura do território, na abordagem geográfica, e habitats, na abordagem ecológica. Nenhuma dessas unidades se caracteriza por ter as propriedades de sistemas.

Ademais, como defendem King (1999) e Allen \& Hoekstra (1992), as ecologias de ecossistemas, comunidades e paisagens podem estar lidando com um mesmo espaço geográfico, mudando apenas o enfoque ou a perspectiva do estudo. Assim, um mesmo objeto de estudo, um fragmento florestal, por exemplo, pode ser estudado sob a ótica de comunidades (i.e., dando ênfase à estrutura e dinâmica das associações de espécies, e às interações entre as populações), a partir da ecologia de ecossistemas (considerando o sistema a partir de relações determinísticas entre a comunidade e o meio abiótico, em particular ressaltando os ciclos de nutrientes e o fluxo de energia) ou numa perspectiva de ecologia de paisagens (buscando entender a estrutura da comunidade através da dinâmica do mosaico florestal, formado pelas manchas de vegetação em diferentes estádios de sucessão e perturbação). Um mesmo objeto, como o fragmento florestal do exemplo, estudado numa mesma escala, pode ser entendido como "comunidade", "ecossistema" ou "paisagem", dependendo da perspectiva do estudo.

\section{Uma nova perspectiva em ecologia}

Não sendo obrigatoriamente nem uma ecologia de macro-escalas nem um novo nível de análise de questões ecológicas, qual é a nova perspectiva trazida pela ecologia de paisagens para a ecologia (dentro da "abordagem ecológica)? Essa nova perspectiva relaciona-se a dois fatores: a influência de padrões espaciais sobre processos ecológicos; e o reconhecimento da influência da escala nos estudos ecológicos.

\section{Relações entre padrões espaciais e processos ecológicos}

$\mathrm{O}$ ponto central da análise em ecologia de paisagens é o reconhecimento da existência de uma dependência espacial entre as unidades da paisagem: o funcionamento de uma unidade depende das interações que ela mantém com as unidades vizinhas (e.g., diferentes tipos de habitats). A ecologia de paisagens seria assim uma combinação de uma análise espacial da geografia com um estudo funcional da ecologia. A problemática central é o efeito da estrutura da paisagem (i.e., o padrão espacial) nos processos ecológicos. Contrariamente à ecologia de ecossistemas, que procura estabelecer ou analisar as relações verticais da biota com o seu ambiente (por exemplo, como a diversidade de uma comunidade de árvores pode ser explicada pelo clima ou tipo de solo?), a ecologia de paisagens dá maior ênfase às relações horizontais (usando o mesmo exemplo, como a comunidade de árvores pode ser explicada em função de seu isolamento a outras comunidades semelhantes, ou em função da existência de um impacto causado pela unidade justo adjacente?). A ecologia de paisagens pode ser assim entendida como uma ecologia de interações espaciais entre as unidades da paisagem.

Nesta perspectiva, fica clara a influência da biogeografia de ilhas na origem desta disciplina. A teoria de ilhas e, mais tarde, a teoria de metapopulações oferecem um arcabouço teórico valioso para relacionar padrão espacial e processos ecológicos. Segundo essas teorias, a configuração espacial, expressa em particular pelo tamanho das manchas da paisagem e pelo grau de isolamento ou de conectividade entre manchas de um mesmo tipo de unidade, é um fator-chave na determinação de uma série de processos ecológicos, como os riscos de extinção e as possibilidades de migração ou (re)colonização (Hanski \& Gilpin 1997).

Os processos ecológicos estudados podem ser tanto foco de estudos da ecologia de populações (natalidade, mortalidade, imigração, por exemplo) ou da interação entre populações (e.g., polinização, dispersão), quanto da ecologia de comunidades (processos de estruturação da comunidade, como a predação ou a competição) ou da ecologia de ecossistemas (produtividade, ciclagem e dispersão de um nutriente), ou mesmo da genética (variabilidade gênica, por exemplo). A ecologia de paisagens lida assim com as mesmas perguntas de outras disciplinas da ecologia, modificando apenas a perspectiva na qual elas são analisadas, inserindo-as num contexto espacial. De certa forma, os ecólogos de paisagens nada mais são do que ecólogos de populações, comunidades ou ecossistemas que abordam suas perguntas nessa nova perspectiva oferecida pela ecologia de paisagens.

Possivelmente, o maior desafio da ecologia de paisagens é de estabelecer uma teoria de mosaicos, 
procurando entender como diferentes padrões de organização espacial de seus constituintes (as unidades da paisagem) influem sobre seu funcionamento. Desta forma, a ecologia de paisagens procura testar uma das propriedades fundamentais da teoria hierárquica. Para tanto, procura distinguir grandes tipos de paisagens, baseado no modelo de mancha-corredor-matriz (Forman 1995). É possível, assim, distinguir paisagens contendo muitos fragmentos grandes (por exemplo, a região do Pontal do Paranapanema onde há grandes fragmentos isolados de floresta mesófila semi-decídua), ou paisagens formadas por uma infinidade de pequenos fragmentos (região da Bragantina, no leste do Pará, onde há grande alternância entre capoeiras de diferentes idades e áreas de agricultura de corte-e-queima), ou por uma rede de corredores (paisagem em Caucaia do Alto, nos municípios de Cotia e Ibiúna, onde foi mantida uma rede de corredores florestais ripários e de corredores artificiais, dividindo propriedades ou parcelas agrícolas), ou por um padrão em tabuleiro de xadrez (áreas agrícolas do Planalto Central Brasileiro, com alternância de tipos de cultura). Além de conseguir identificar esses padrões, o grande desafio é entender as suas implicações em termos de funcionamento da paisagem.

\section{Importância da escala}

O principal interesse da ecologia de paisagens, como mencionado anteriormente, está relacionado com o estudo da heterogeneidade. No entanto, o reconhecimento da homogeneidade ou heterogeneidade de um objeto está diretamente ligado à questão da escala: praticamente qualquer porção de terra é homogênea numa escala mais abrangente e heterogênea quando vista numa escala mais detalhada.

A palavra escala é utilizada para se referir a diferentes noções: a escala espacial inclui um aspecto de extensão no espaço (por exemplo, uma área de estudo pode ter 1 ou $100 \mathrm{~km}^{2}$ ) e de resolução na informação que é obtida (por exemplo, ao trabalhar com imagens Thematic Mapper do satélite LANDSAT é possível obter informações a cada $30 \mathrm{~m}$; com o satélite NOAA, a informação sobre características da terra são obtidas apenas a cada $1,1 \mathrm{~km}$ ); a escala temporal inclui também um aspecto de duração (tempo de análise) e resolução (freqüência de obtenção de dados); a escala geográfica indica as dimensões de representação de um objeto no solo (por exemplo, a escala de 1/10.000 indica que $1 \mathrm{~cm}$ no mapa corresponde a 10.000 cm ou $100 \mathrm{~m}$ no solo ); a escala de percepção das espécies refere-se à escala espacial e temporal na qual a espécie em estudo percebe ou interage com a paisagem (i.e., qual a extensão do seu território ou qual é a área de paisagem que age sobre essa espécie?; com que detalhamento a espécie percebe variações no seu habitat?).

Há duas questões ecológicas básicas quando se pensa na questão de escala: i) existe uma escala espacial e temporal determinada para cada processo ecológico ou para cada espécie?; ii) é possível transpor resultados obtidos numa escala pontual para uma escala global?
A primeira pergunta estaria baseada na existência de escalas espaciais e temporais corretas para se observar determinados fenômenos. Assim, uma determinada espécie, em função de suas capacidades de deslocamento através da paisagem, de suas exigências de habitats específicos e de suas interações com outras espécies tenderia a perceber a paisagem numa determinada escala. Em particular, espécies com pequena capacidade de deslocamento ou dispersão vão perceber a paisagem num contexto mais local, ao contrário de espécies com maior capacidade de deslocamento, que tenderão a perceber a paisagem num contexto mais amplo; ou ainda espécies com habitats muito especializados que tenderão a ver a paisagem com um grau maior de detalhamento em relação a espécies mais generalistas. Em parte isso tem sido confirmado com estudos de campo. Por exemplo, num trabalho com fragmentos florestais no rio Jacaré-Pepira, a riqueza de espécies de árvores barocóricas apresentou relações mais significativas com parâmetros da paisagem próxima (num raio de $2 \mathrm{~km}$ ) em relação a espécies anemocóricas e, principalmente, zoocóricas, que apresentaram relações mais intensas com a paisagem num raio de 4 a $8 \mathrm{~km}$ (Metzger 2000). No entanto, as evidências ainda são escassas e novos estudos, com outros grupos de organismos e numa ampla gama de paisagens, devem ser conduzidos a fim de se obter generalizações.

A segunda pergunta envolve um dilema fundamental da pesquisa ecológica: a maior parte dos dados científicos é obtida em escalas locais, enquanto a demanda por respostas a problemas ambientais ocorre principalmente em escalas globais (por exemplo, aquecimento climático, fragmentação e perda de biodiversidade, uso sustentável da água). Há assim uma carência de dados e uma urgência de respostas em escalas globais. Muitas vezes, a obtenção de dados em escalas globais é extremamente problemática. No caso da ecologia de paisagens, há uma grande dificuldade de se estabelecer experimentos em escalas espaciais e temporais amplas. Não existem réplicas verdadeiras (cada paisagem é única), nem controles, e há uma grande dificuldade de se promover alterações visando o estudo científico de seus impactos (Bissonete 1997, Metzger no prelo). O principal caminho para a resolução desse dilema estaria no descobrimento de regras de transposição de resultados obtidos em escalas locais para escalas globais. Assim, relações entre padrões e processos biológicos poderiam ser analisados em microescala, onde há uma maior possibilidade de controle das variáveis, e os resultados seriam inferidos para as escalas mais amplas. No entanto, essas regras de transposição não obedecem sempre a leis lineares ou a propriedades fractais, tendo sido observado limiares de validade nas relações entre padrões e processos. A esse fenômeno é dado o nome de "efeito de transmutação": mudanças nas propriedades em função da mudança de escala ou de nível hierárquico (Bissonette 1997). Haveria assim domínios de escala nas quais as relações entre padrões e processos são válidas, sendo que esses domínios dependeriam de uma combinação das escalas espaciais, temporais e de 
percepção das espécies. De um domínio para o outro, as relações mudam de forma não previsível por modelos matemáticos simples, lineares. Esse é o segundo grande desafio da ecologia de paisagens: ser capaz de entender e transpor as relações entre padrões e processos de um domínio de escala para outro.

\section{Qual a contribuição aplicada da ecologia de paisagens?}

Em termos aplicados, argumenta-se que a ecologia de paisagens pode contribuir pois se propõe a lidar com mosaicos antropizados, na escala na qual o homem está modificando o seu ambiente. $\mathrm{Na}$ "abordagem geográfica", mais do que uma análise detalhada de impactos locais (principal enfoque da ecologia de ecossistemas e de comunidades), a ecologia de paisagens procura entender as modificações estruturais, e portanto funcionais, trazidas pelo homem no mosaico como um todo, incorporando de forma explícita toda a complexidade das inter-relações espaciais de seus componentes, tanto naturais quanto culturais. $\mathrm{Na}$ "abordagem ecológica", apesar de focar mais as unidades "naturais", mais uma vez a ecologia de paisagens situa-se na escala correta para responder aos principais problemas ambientais, tanto relacionados à fragmentação de habitats quanto ao uso inadequado dos solos e da água. Para compatibilizar uso das terras e sustentabilidade ambiental, social e econômica, é necessário planejar a ocupação e a conservação da paisagem como um todo. Por exemplo, a proteção de apenas um fragmento de vegetação ou um trecho do rio não é suficiente se o entorno do fragmento ou as cabeceiras estiverem comprometidas. O homem está na origem dos problemas ambientais, mas é parte também das soluções. Resolver o problema da perda da biodiversidade excluindo o homem da paisagem é apenas um paliativo, e não uma solução.

Em poucas palavras, ao lidar com a paisagem como um todo, considerando as interações espaciais entre unidades culturais e naturais, incluindo assim o homem no seu sistema de análise, a ecologia de paisagens adota uma perspectiva correta para propor soluções aos problemas ambientais.

\section{Conclusões}

Apesar de existirem duas abordagens distintas dentro da ecologia de paisagens, elas apresentam muito em comum, como o fato de serem espacialmente explícitas, lidarem com espaços heterogêneos e considerarem múltiplas escalas em suas análises. Na noção integradora proposta no presente trabalho, a paisagem continua sendo uma entidade visual, totalmente dependente do observador, em particular da escala de observação.

No plano teórico, a principal contribuição da ecologia de paisagens é o enfoque nas relações entre padrões espaciais e processos ecológicos e a incorporação da escala nas análises. Essa mudança de enfoque pode ser considerada uma mudança de paradigma dentro da ecologia. No entanto, a ecologia de paisagens ainda terá que vencer grandes desafios, como o estabelecimento de um arcabouço teórico (uma teoria de mosaicos) e a transposição do problema de transmutação.

No plano aplicado, pelo fato da ecologia de paisagens se posicionar de forma adequada para responder aos problemas ambientais, é possível antever, num futuro próximo, um crescimento explosivo da ecologia de paisagens em países tropicais, de forma similar ao que ocorreu recentemente em regiões temperadas, pois a resposta aos problemas ambientais, relacionados à fragmentação de habitats tropicais, expansão de fronteiras agrícolas e uso da água, é mais do que nunca urgente.

\section{Agradecimentos}

Eu gostaria de agradecer Rozely dos Santos, Vânia Pivello, Waldir Mantovani e Alexandre Martensen que contribuíram muito para a melhoria deste texto através de comentários, sugestões e correções pertinentes feitas numa versão anterior. Também sou grato aos meus alunos de graduação e pós-graduação, que têm propiciado valiosos questionamentos e enriquecedoras discussões.

Anexo: Pequeno glossário de termos usualmente utilizados em ecologia de paisagens. As definições, utilizadas ao longo do texto, seguem o que é proposto na "abordagem ecológica”.

Borda. Área de transição entre duas unidades da paisagem. Conectividade. Capacidade da paisagem (ou das unidades da paisagem) de facilitar os fluxos biológicos. A conectividade depende da proximidade dos elementos de habitat, da densidade de corredores e "stepping stones", e da permeabilidade da matriz.

Corredores. Áreas homogêneas (numa determinada escala) de uma unidade da paisagem, que se distinguem das unidades vizinhas e que apresentam disposição espacial linear. Em estudos de fragmentação, considera-se corredor apenas os elementos lineares que ligam dois fragmentos anteriormente conectados.

Elemento da paisagem. Trata-se de cada mancha, corredor ou área da matriz. Uma unidade da paisagem pode apresentar vários elementos numa paisagem. Por exemplo, uma unidade "mata" pode ter vários fragmentos e alguns corredores.

Escala de percepção. Escala espacial e temporal na qual cada espécie percebe a paisagem em função de suas características ecológicas (tamanho de território, especificidade do habitat, capacidade de locomoção, etc.).

Escala espacial. É definida por características de extensão (tamanho) e resolução (unidade mínima de representação espacial). Os mapas variam de escalas pontuais e finas (mapas detalhados, com alta resolução e, em geral, extensão reduzida) para escalas globais e grosseiras (mapas com poucos detalhes, com resolução grosseira e, em geral, ampla extensão). 
Fragmento. Uma mancha originada por fragmentação, i.e. por sub-divisão, promovida pelo homem, de uma unidade que inicialmente apresentava-se sob forma contínua, como uma matriz.

Manchas. Áreas homogêneas (numa determinada escala) de uma unidade da paisagem, que se distinguem das unidades vizinhas e têm extensões espaciais reduzidas e não-lineares.

Matriz. Unidade da paisagem que controla a dinâmica da paisagem (Forman 1995). Em geral essa unidade pode ser reconhecida por recobrir a maior parte da paisagem (i.e., sendo a unidade dominante em termos de recobrimento espacial), ou por ter um maior grau de conexão de sua área (i.e., um menor grau de fragmentação). Numa segunda definição, particularmente usada em estudos de fragmentação, a matriz é entendida como o conjunto de unidades de não-habitat para uma determinada comunidade ou espécie estudada.

Mosaico. Uma paisagem que apresenta uma estrutura contendo mancha, corredores e matriz (pelo menos dois desses elementos).

Paisagem. Mosaico heterogêneo formado por unidades interativas, sendo esta heterogeneidade existente para pelo menos um fator, segundo um observador e numa determinada escala de observação. Uma paisagem pode se apresentar sob forma de mosaico, contendo manchas, corredores e matriz, ou sob forma de gradiente.

Sistema fractal. Sistema que mantém suas características/propriedades em diferentes escalas.

Stepping stone (em português, "pontos de ligação" ou "trampolins ecológicos"). Pequenas áreas de habitat dispersas pela matriz que podem, para algumas espécies, facilitar os fluxos entre manchas.

Unidade da paisagem. Cada tipo de componente da paisagem (unidades de recobrimento e uso do território, ecossistemas, tipos de vegetação, por exemplo). (Obs.: Na abordagem geográfica, a unidade da paisagem é em geral definida como um espaço de terreno com características hidro-geomorfológicas e história de modificação humana semelhantes. De certa forma, a "unidade da paisagem" da abordagem geográfica pode ser considerada como uma "paisagem" dentro da abordagem ecológica, pois ela é composta por um mosaico com diferentes usos e coberturas.).

\section{Referência}

Allen, T.F.H. \& Hoekstra, T.W. 1992. Toward a unified ecology. Complexity in ecological systems. Columbia University Press, New York.

Barrett, G.W. \& Bohlen, P.J. 1991. Landscape ecology. In: Hudson, W.E. (Ed.). Landscape linkages and biodiversity. Island Press, Washington, DC. pp. 149-161.
Bissonette, J.A. 1997. Scale-sensitive ecological properties: historical context, current meaning. In: Bissonette, J.A. (Ed.). Wildlife and landscape ecology: effects of pattern and scale. Springer-Verlag, New York. pp. 3-31.

Delpoux, M. 1974. Métodos em questão: ecossistema e paisagem. Instituto de Geografia, Universidade de São Paulo, São Paulo, 23 p.

Forman, R.T.T. 1995. Land mosaics: the ecology of landscapes and regions. Cambridge University Press, Cambridge.

Forman, R.T.T. \& Godron, M. 1986. Landscape ecology. Wiley \& Sons Ed., New York.

Gonzales A., Lawton J.H., Gilbert F.S., Blackburn T.M. \& Evans-Freke I. 1998. Metapopulation dynamics abundance and distribution in micro ecosystems. Science 281: 2045-2047.

Gustafson, E.J. 1998. Quantifying landscape spatial pattern: what is the state of the art? Ecosystems 1:143-156.

Hanski, I. A. \& Gilpin, M. E. 1997. Metapopulation biology: ecology, genetics, and evolution. Academic Press, San Diego-London.

Hobbs, R.J. 1994. Landscape ecology and conservation: moving from description to application. Pacific Conservation Biology 1: 170-176.

Joly, P. Miaud, C., Lehmann, A. \& Grolet, O. 2001. Habitat matrix effects on pond occupancy in Newts. Conservation Biology 15: 239-248.

King, A.W. 1999. Hierarchical theory and the landscape.... Level? Or: words do matter. In: Wiens, J. \& Moss, M.R. (Ed.). Issues in landscape ecology. IALE, Colorado. pp.6-9.

McGarigal, K. \& Marks, B.J. 1995. FRAGSTATS: spatial pattern analysis program for quantifying landscape structure. U.S. Forest Service General Technical Report PNW 351.

Metzger, J.P. 2000. Tree functional group richness and spatial structure in a tropical fragmented landscape (SE Brazil). Ecological Applications 10: 11471161.

Metzger, J.P. Delineamento de experimentos numa perspectiva de ecologia da paisagem. In: Cullen Jr., L., Rudy, R., Valladares-Padua, C. (eds.). Manual em Técnicas na Biologia da Conservação e no Manejo da Vida Silvestre. IPÊ, Smithsonian Institution, National Zoological Park. No prelo.

Naveh, Z. \& Lieberman, A. 1994. Landscape ecology: theory and application. Springer-Verlag, New York.

Odum, E.O. 1971. Fundamentals of ecology. Saunders, Philadelphia, Pennsylvania.

Pojar, J., Diaz, N., Steventon, D., Apostol, D. \& Mellen, K. 1994. Biodiversity planning and forest management at the landscape scale. In: Huff, M.H., Norris, L.K., Nyberg, J.B. \& Wilkin, N.L. (Coords.). Expanding horizons of forest ecosystem management. Proceedings of the third "Habitat Futures Workshop". Department of Agriculure, Forest Service, Pacific Northwest Research Station, Portland, OR. pp. 55-70. 
Renjifo, L.M. 2001. Effect of natural and anthropogenic landscape matrices on the abundance of subandean bird species. Ecological Applications 11: 14-31.

Riitters, K.H., O'Neill, R.V., Hunsaker, C.T., Wikham, J.D., Yankee, D.H., Timmins, S.P., Jones, K.B. \& Jackson, B.L. 1995. A factor analysis of landscape pattern and structure metrics. Landscape Ecology 10: 23-39.

Risser, P.G., Karr, J.R. \& Forman, R.T.T. 1984. Landscape ecology, directions and approaches. Illinois Natural History Surveys. Special Publications, 2: $1-18$.

Summerville, K.S. \& Crist, T.O. 2001. Effects of experimental habitat fragmentation on patch use by butterflies and skippers (Lepidoptera). Ecology 82: $1360-1370$.

Tansley, A.G. 1935. The use and abuse of vegetational concepts and terms. Ecology 16: 284-307.

Tricart, J.J.L. 1979. Paysage et écologie. Revue de Géomorphologie dynamique: géodynamique externe. Études intégrée du milieu naturel, XXVIII, n.3, p. 81-95.

Troll, C. 1971. Landscape ecology (geo-ecology) and biogeocenology: a terminological study. Geoforum 8: 43-46.

Troppmair, H. 2000. Ecologia da paisagem: uma retrospectiva. Anais do I Fórum de debates "Ecologia da Paisagem e Planejamento Ambiental" (4-8 junho de 2000, Rio Claro). Sociedade de Ecologia do Brasil.

Turner M.G. 1989. Landscape ecology : the effect of pattern on process. Annual Review of Ecology and Systematic 20: 171-197.

Turner M.G. \& Gardner R.H. (Eds.). Quantitative methods in landscape ecology: the analysis and interpretation of landscape heterogeneity. Springer-Verlag, New York.

Urban, D. O'Neill, R.V. \& Shugart, H.Jr. 1987. Landscape ecology: a hierarchical perspective can help scientists understand spatial patterns. BioScience 37: 119-127.

Wiens, J.A. 1996. Challenges for the future. IALE Bulletin 14: $1-2$.

Wiens, J.A. 1999. Toward a unified landscape ecology. In: Wiens, J. \& Moss, M.R. (Ed.). Issues in landscape ecology. IALE, Colorado. pp.148-151.

Wiens, J.A. \& Milne, B.T. 1989. Scaling of "landscapes" in landscape ecology, or, landscape ecology from a beetle's perspective. Landscape Ecology 3: 87-96.

Wiens, J.A., Stenseth, N.C., Van Horne, B. \& Ims, R.A. 1993. Ecological mechanisms and landscape ecology. Oikos 66: 369-380.
Título: O que é ecologia de paisagens ?

Autor: Jean Paul Metzger

Biota Neotropica, Vol. 1, números 1 e 2, 2001 http://www.biotaneotropica.org.br/v1n12/pt/abstract?the matic-review+BN00701122001

Recebido em 01 de outubro de 2001

Publicado em 28 de novembro de 2001

ISSN 1676-0603 